\title{
Propositions and the Metaphysics of Time
}

Giuliano Torrengo
University of Milan

The central point of Brogaard's interesting essay is that temporalism, roughly, the thesis that there are propositions whose evaluation is sensitive to time (14), is a better alternative to standard semantic eternalism, roughly, the thesis that no proposition is sensitive to temporal variation. Five theoretical roles individuate propositions: (i) semantic values of sentences, (ii) objects of attitudes, (iii) objects of agreement and disagreement, (iv) what is transferred in successful communication, and (v) what intensional operators operate on (5-6, 30). For each of those roles Brogaard aims at showing that temporal propositions fare better than eternal ones, in that the problems that have been traditionally raised against them can be overcome, while more serious problems can be raised against eternal propositions. Although most of the book touches upon issues of philosophy of language and philosophy of mind, as it should be, there are several considerations that Brogaard makes about the relation between the semantic tenets of temporalism and eternalism, on the one side, and the metaphysics of time, on the other. In this note, I will assume that the semantic arguments in the book for preferring temporalism over eternalism are sound, and confine myself to some criticism concerning their metaphysical import.

In the introduction, Brogaard points out that semantic eternalism is metaphysically more demanding than temporalism, since it entails metaphysical eternalism, namely the view that past and future times are ontologically on a par with the present — or at least because it rules out presentism, the thesis that only present entities exist (6-7). The reason is that eternal propositions can contain non-present times as constituents. Assuming that the existence of a proposition entails the 
existence of its constituents, it follows that eternal propositions containing reference to non-present times are incompatible with presentism. Of course, a presentist could think of times as some sort of ersatz entities, namely sets of temporal propositions. But the propositions that individuate times are temporal propositions, and thus they are not at the semantic eternalist's disposal (see 7, note 4).

I agree with Brogaard's remarks. Indeed, while there is no immediate objection to the use of ersatz times as parameters of the circumstances of evaluation that the presentist makes, appealing to a set of propositions as a constituent of a proposition seems suspiciously circular. However, I do not think that those arguments can be used to support temporalism, at least the variety of temporalism defended in the book. Here is the problem: semantic eternalism is supposed to put stricter constraints on the choice of a metaphysics of time than temporalism. However, it is the thesis that some eternal propositions exist that is at odds with presentism, rather than the stronger thesis that all propositions are eternal. And many temporalists do admit that not all propositions are temporal. Brogaard herself defends a version of temporalism in which eternal propositions that make reference to non-present times are accepted (155-57). Maybe I am wrong and presentism is compatible after all with propositions that make explicit reference to a non-present time. But if I am wrong, because presentist can resort to ersatz times as constituents of propositions, say, then it seems that semantic eternalism is compatible with presentism after all. I can imagine an 'in between position' to the effect that the temporalist can accept ersatz times as constituents of eternal propositions, while the eternalist cannot. But I do not think this view is very appealing, and it is defended nowhere in the book.

Be that as it may, I have another concern with respect to how Brogaard characterizes the relation between semantic eternalism and metaphysical eternalism. According to her: 'semantic eternalism [...] makes it difficult for metaphysical eternalists to articulate the commitment of their theories' (7). This thesis is first stated in the introduction and then elaborated at length in Chapter 7. Here is what I take to be the core's of Brogaard's position. Presentists and eternalist are taken to disagree on whether wholly past objects, such as Socrates, exist. Thus, a way to state their disagreement is to say that they disagree on how (2) below [Chapter 7's numeration] is evaluated 
when uttered, say, in 2013.

(2) Socrates exists.

However, ordinarily understood, (2) is taken to convey that Socrates is located roughly in the same spatiotemporal location in which we are, and thus we can meet him as we meet our friends. Both the eternalist and the presentist agree on the falsity of this reading. In the literature, many agree that in order to avoid a skeptical outcome with respect to the substantivity of the eternalism/presentism distinction, something like such a 'philosophy room reading' of (2) must be at both the eternalist's and the presentist's disposal ${ }^{1}$. Roughly the idea is that what the eternalist means with (2), when she disagrees on the truth value of an utterance of (2) in 2013 with the presentist, is that quantifying unrestrictedly — in particular, without any restriction on the temporal dimension - (2) expresses a true proposition.

Now, why, according to Brogaard, is the metaphysical eternalist who also endorses semantic eternalism in trouble? The idea is that from eternalism it follows that any tensed sentence expresses an eternal proposition relative to its context of utterance. Thus, (2) as uttered at time $t^{*}$ expresses the proposition that is more perspicuously expressed by (2a) below.

(2a) Socrates exists at $t^{*}$.

However, (2a) seems to be as ambiguous as (2), and thus it does not qualify as a good analysis of the 'philosophy room' reading of (2). Providing that a minimal condition on a good analysis is to yield an unambiguous paraphrase. Brogaard's proposal is to endorse temporalism instead, and to allow for two readings of (2) in terms of the proposition that they express. According to the first reading - the ordinary reading - (2) expresses a temporal proposition that gets evaluated at the time of utterance. In this reading, both the presentist and the eternalist agree that (2) is false. According to the second

\footnotetext{
${ }^{1}$ See Zimmermann 1998, Oaklander 2002, Sider 2006, Tallant 2013 and the debate between Crisp 2004a, 2004b and Ludlow 2004. Meyer 2005, Savitt 2006, Dorato 2006, Callender 2011 hold a sceptical position.
} 
reading — the philosophy room reading — (2) expresses an eternal proposition that only the eternalist accepts as true.

I have three qualms here, the first and the last with Brogaard's positive proposal, and the second with her criticism of eternalism's expressive capacity. As for the first qualm, according to Brogaard, and coherently with her view, the eternal proposition that Socrates exists is evaluable as true or false simpliciter only in a context in which either Socrates is an instantaneous object, or Socrates always (or never) exists (150). But then, if Socrates is not a instantaneous object, the presentist cannot claim that (2) is false in the philosophical room reading. She can disagree with the eternalist only in the sense that she does not accept (2) as true. Maybe that's enough for making the disagreement substantial, but if an alternative accounts in which (2) turns out false is available to the presentist, there seem to be reasons to prefer it. I understand that Brogaard endorses four-dimensionalism as a theory of persistence, and thus she does have an account in which the eternal reading of (2) is false simpliciter, since she maintains that in that reading (2) is about a instantaneous temporal slice of Socrates. However, dialectically, the fact that if one assumes temporalism, then one must endorse a particular thesis about persistence in order to express a distinction about temporal ontology seems to me a drawback of temporalism.

Secondly, it is not clear to me why the fact that a sentence such as (2a) is ambiguous between a restricted reading and an unrestricted reading of the quantifier counts as evidence against semantic eternalism. Brogaard's worry seems to be that the role of the time of utterance $t^{*}$ in the proposition expressed is unclear. But once we accept the distinction between a temporally restricted and a temporally unrestricted reading of quantification (and something analogous for predication), the worry is spurious. The role of the temporal parameter provided by the context within the content expressed depend on the particular form of semantic eternalism, but in no case it will determine a restriction on the quantifier on an unrestricted reading of the quantifier. Of course, if the quantifier is understood as temporally restricted, then the time of utterance together with tenses and possibly other (pragmatic and semantic) elements will determine the restriction. But if we agree that the distinction between temporally restricted and temporally unrestricted interpretation of the quanti- 
fier is understood, then Brogaard's complain vanishes.

Generally speaking, the problem of articulating the commitments of presentism and eternalism seems to me orthogonal to the debate on temporalism vs. eternalism. In order to state the disagreement between the presentist and the eternalist, we need to understand (2) in such a way that the extension of 'exist' is not limited by temporal factors ${ }^{2}$. Once we grasp this unrestricted construal of 'exist', if we are temporalists, we will take the claim to express a temporally neutral proposition to be evaluated relative to the time of utterance; if we are eternalist, we will take it to express a content that is indexed to the time of utterance, and thus temporally invariant. Maybe many metaphysical eternalists, after having read Brogaard's semantic arguments in favor of temporalism, will decide to endorse her view (I may be one of them), but semantic eternalism as such is not an obstacle to understanding temporally unrestricted quantification.

What would be an obstacle to articulate presentism and eternalism is ruling out by semantics alone the possibility that what exists simpliciter, namely unrestrictedly speaking, changes over time. The core of the distinction after all is that according to the eternalism what exists simpliciter never changes through time, whereas for the presentist it does. And it is important that such claims be stated by using the same language, which would be impossible if the language itself ruled out one of the two positions. But semantic eternalism does not rule out this possibility, in so far as it allows for tensed sentences to express claims of existence simpliciter. This leads me to my last worry.

When the eternalist refers to presently existing things, it seems natural to think that the agreement with the presentist is not confined only to the ordinary readings of the claims (on whose truthvalue she agrees with the presentist also in the case of past entities), but it also reaches the unrestricted reading. But this does not seem to be the case if the unrestricted reading is interpreted as the reading that expresses an eternal proposition that does not contain a time constituent, as Brogaard maintains (148). The reason is that Brogaard is compelled to maintain that existential eternal propositions about non eternal entities are never true for the presentist, not even when uttered when the entity at issue is present. Therefore,

${ }^{2}$ I have argued that in Torrengo 2012. 
there is a sense in which the presentist and the eternalist necessarily disagree on what presently exists, which seems to me a weird outcome of the view.

Imagine the following situation. A presentist and an eternalist find themselves in a biology lab. A scientist is observing through a microscope an amoeba (call it 'Amoeba'), which is about to undergo a process of a mitosis. Suppose that at $t$, Amoeba has not undergone mitosis, while at $t$ ' the process is complete, and assume that individual amoebas do not survive processes of mitosis (choose some other fatal event for protozoa otherwise). Consider now claim (1) below, and imagine that the eternalist utters it once at $t$ and a second time at $t^{\prime}$.

(1) Amoeba exists.

In the ordinary reading, the presentist and the eternalist agree that (1) is true when uttered the first time (at $t$ ), and false when uttered the second time (at $t^{\prime}$ ). In the philosophy room reading, the two will disagree at $t^{\prime}$ : according to the eternalist, the eternal proposition that Amoeba exists is true at $t^{\prime}$, whereas the same cannot be said of the presentist. But what about an utterance of (1) at $t$ in the unrestricted reading? According to Brogaard's proposal, it should be taken to express a eternal proposition with no time index, which has the same truth vale with respect to $t$ and $t^{\prime}$. This is fine for the eternalist, who evaluates both utterances of the unrestricted reading as true. But it is bad news for the presentist. Since she does not accept (1) as true at $t$ ' in the unrestricted reading, she is compelled to do the same with an utterance of (1) at $t$ - the eternal proposition expressed in both contexts being the same. Can't we say that the presentist at $t$ agrees with the eternalist that Amoeba exists simpliciter? No, because, again, that would entail that Amoeba will exist simpliciter at $t$ ' too (160). Notice that according to the 'standard' semantic eternalist, utterances of tensed sentences such as (1) express time indexed eternal proposition. Thus, an utterance of the same sentence expresses different (time indexed) eternal propositions on different occasions, even when read unrestrictedly. This is good news, because it allows us to express the key difference between the presentist, who takes unrestricted existential claim to vary over time, and the eternalist, who does not. Finally, Brogaard argues convincingly that for the roles that proposi- 
tions usually have in philosophy of language and mind the best option is often to endorse temporalism. However, when it comes to metaphysics, the traditional eternalist approach looks to me on more steady ground.

Giuliano Torrengo Università degli Studi di Milano Dipartimento di Filosofia via Festa del Perdono, 7 20122 - Milano Italy giuliano.torrengo@unimi.it

\section{References}

Callender, C. 2011. Time's Ontic Voltage. In The Future of Philosophy of Time, ed. by Adrian Bardon. London \& New York, Routledge.

Crisp, T. 2004a. On Presentism and Triviality. In Oxford Studies in Metaphysics, ed. by D. Zimmerman, 1 15-20

Crisp, T. 2004b. Reply to Ludlow. In Oxford Studies in Metaphysics, ed. by D. Zimmerman, $137-46$

Dorato, M. 2006. The irrelevance of the presentist/eternalist debate for the ontology of Minkowski spacetime. In The Ontology of Spacetime, ed. by D. Dieks, 93-109. Elsevier.

Ludlow, L. 2004. Presentism, Triviality, and the Varieties of Tensism. In Oxford Studies in Metaphysics, ed. by D. Zimmerman, 1 21-36

Mever, U. 2005. The Presentist's Dilemma. Philosophical Studies, 122: 213-225

Oaklander, N. 2002. McTaggart's Paradox Defended. Metaphysica: International Journal of Ontology and Metaphysics, 3, 1: 11-25

Savitt, S.F. 2006. Presentive and Eternalism in Perspective. In The Ontology of Spacetime, ed. by D. Dieks, Elsevier (http://philsci-archive.pitt.edu/archive/00001788/01/PEP.pdf)

Tallant, J.C. 2013. Defending Existence Presentism. Forthcoming in Erkenntnis

Sider, T. 2006. Quantifiers and Temporal Ontology. Mind 115 (457): 75-97

Torrengo, G. 2012. Time and Simple Existence. Metaphysica, 13: 125-130

Zimmerman, D. 1998. Temporary Intrinsics and Presentism. In Metaphysics: The Big Questions, ed. by P. van Inwagen and D. Zimmerman, 206-219. Malden (Mass.), Blackwell. 